\title{
Magnitude of Anemia and Associated Factors among HIV-Infected Children Receiving Antiretroviral Therapy in Pastoral Community, Ethiopia: A Retrospective Cross-Sectional Study
}

\author{
Getahun Fentaw Mulaw $\mathbb{D}^{1},{ }^{1}$ Fatima Ahmed Yesuf, ${ }^{2}$ and Haftom Temesgen Abebe ${ }^{3}$ \\ ${ }^{1}$ Department of Public Health, College of Medical and Health Sciences, Samara University, Samara, Afar, Ethiopia \\ ${ }^{2}$ Afar Regional Health Bureau, Samara, Afar, Ethiopia \\ ${ }^{3}$ Department of Biostatistics, School of Public Health, College of Health Sciences, Mekelle University, Mekelle, Ethiopia
}

Correspondence should be addressed to Getahun Fentaw Mulaw; gechfentaw1014@gmail.com

Received 8 April 2020; Revised 25 July 2020; Accepted 17 September 2020; Published 30 September 2020

Academic Editor: Estella M. Matutes

Copyright (C) 2020 Getahun Fentaw Mulaw et al. This is an open access article distributed under the Creative Commons Attribution License, which permits unrestricted use, distribution, and reproduction in any medium, provided the original work is properly cited.

\begin{abstract}
Background. The two major comrbidities (anemia and poor nutrition) are common manifestations of HIV-infected children, which threaten their lives. In Ethiopia, there is limited information on the magnitude and factors associated with anemia among HIVinfected children. Thus, this study was aimed to determine the magnitude and factors associated with anemia among HIV-infected children receiving antiretroviral therapy in the Afar region, Ethiopia. Methods. A cross-sectional retrospective record review was conducted on a sample size of $102 \mathrm{HIV}$-infected children aged 6 months to $<15$ years in selected ART sites of the Afar region from May 1 to 25, 2018. Patient cards from 2009 to 2017 with the required information were considered. A paired sample $t$-test was used to assess whether there is a significant difference in the hemoglobin level before and after the HAART regimen. Multivariable logistic regression was used to determine predictors of anemia. Statistical significance was determined at $p$ value $<0.05$. Result. At baseline, $53.9 \%$ of study participants were anemic, from which $8.7 \%, 36.3 \%$, and $9.8 \%$ were mild, moderate, and severe, respectively. There was a statistically significant improvement of hemoglobin level following the one-year course of ART treatment from $10.67 \pm 1.82$ to $11.5 \pm 1.5$ ( $p$ value $\leq 0.001)$ : an improvement of $0.83 \pm 1.74$. Children who were moderately and severely stunted were more than five $(\mathrm{AOR}=5.16,95 \% \mathrm{CI}(1.71,15.56))$ and more than twelve $(\mathrm{AOR}=12.45,95 \% \mathrm{CI}(2.62,59.21))$ times more likely to be anemic than children who were not stunted, respectively. Children whose mothers had not attended ANC follow-up were more than three $(\mathrm{AOR}=3.68,95 \% \mathrm{CI}(1.38,9.81))$ times more likely to be anemic than children whose mothers attended ANC. Children who were in clinical stages 3 and 4 were more than five $(\mathrm{AOR}=5.07,95 \% \mathrm{CI}(1.79,14.37))$ times more likely to be anemic than children who were in clinical stage 1 and 2. Conclusion. The magnitude of anemia among HIV-infected children was found to be high, which is $53.9 \%$. Nutritional status (stunting), WHO clinical stage, and history of ANC follow-up were the predictors significantly associated with childhood anemia. Thus, interventions for HIV-infected children should consider those factors.
\end{abstract}

\section{Background}

Anemia is a condition in which the number of red blood cells (and consequently their oxygen-carrying capacity) is insufficient to meet the body's physiologic needs [1]. Numerically, it is defined as a hemoglobin concentration of less than $11 \mathrm{~g} / \mathrm{dl}$ [2]. Hematological complications have been documented to be the second most common cause of morbidity and mortality in HIV-infected individuals [3]. Anemia is the most common hematological complication of
HIV-infection that has a significant impact on the quality of life and clinical outcomes $[4,5]$.

The estimates of anemia prevalence among HIV-infected individuals in sub-Saharan Africa range from $70-90 \%$, as compared to $20-60 \%$ in developed countries [6-8]. The high prevalence of anemia in HIV-infected children in developing countries may be attributed to endemic malnutrition, helminths infections, tuberculosis (TB), malaria, a different spectrum of opportunistic infections, and poor socioeconomic status [1,9-12]. Studies showed that anemia in 
children with HIV depends on several factors such as the stage of HIV infection, reduced dietary intake (iron, folic acid, and vitamin B12), altered absorption, concurrent illness such as malaria and hookworm, and other infections [12-14]. It may also be caused by HIV/AIDS itself, HAART, and autoimmune destruction of erythrocytes $[10,12,15]$.

Anemia has been a significant predictor of progression to AIDS, and several studies have shown that as hemoglobin levels decrease, the risk of HIV disease progression increases, and it is associated with an increased risk of death in children [16-18]. Anemia is independently associated with decreased quality of life, accelerated disease progression, and increased mortality in HIV-infected individuals [17-20].

Although there are few studies on the magnitude of anemia and associated factors among HIV-infected children in Ethiopia, there are variations in magnitude and associated factors across settings, and also there have been no studies done in the pastoralist regions of the country. Therefore, this study tried to assess the magnitude of anemia and associated factors among HIV-infected children receiving antiretroviral therapy (ART) in selected health institutions of the Afar region.

\section{Methods}

2.1. Study Setting and Design. The study was done in health institutions of the Afar region, Ethiopia. An institutionalbased retrospective document review was done from May 1 to 25, 2018, on HIV-infected children who had attended ART from 2009 to 2017. The Afar region is administratively divided into five zones and 32 districts, and Samara is the administrative capital of the region.

2.2. Sample Size and Sampling Technique. There were 25 government health facilities (public hospitals and health centers) actively providing ART services for HIV-infected persons (both adults and children) in the region. Out of these, HIV-infected children, who were on ART, were found only in 12 health facilities. Therefore, from those 12 health facilities, six health facilities (two hospitals and four health centers) were selected randomly. Then, using a universal sampling method, all HIV-infected children in those ART sites/health facilities from the very beginning of the service provision were considered. Then, only $102 \mathrm{HIV}$-positive children getting ART service had found with the required full documentation. First, children's cards who had received ART drugs for at least one year were selected. Then, the cards were screened based on having full documentation. After all, using the checklist, the required information is recorded (Figure 1).

2.3. Study Variables. The potential study variables were classified into four groups. Those were sociodemographic (child age, sex, and residence), nutritional status (anemia status, underweight, wasting, and stunting), HIV infection (viral load, WHO clinical stage, CD4 count, immunosuppression, opportunistic infections, and length of stay on HAART), and childhood illness (pneumonia, measles, malaria, and tuberculosis).
2.4. Data Collection Techniques and Tools. Data were collected using a structured questionnaire/checklist based on indicators that can be documented on children's pre- and post-ART cards. Pretesting was done in $5 \%$ of the calculated sample size in nonselected ART sites of the region, and then the necessary modifications were done accordingly. Children's anemia status was determined using the WHO's anemia classification based on age. Children aged 6-59 months, 5-11 years, and $12-<15$ years were considered anemic if their hemoglobin level is less than $11 \mathrm{~g} / \mathrm{dl}, 11.5 \mathrm{~g} /$ $\mathrm{dl}$, and $12 \mathrm{~g} / \mathrm{dl}$, respectively $[16,21]$.

Children's clinical stage of HIV is also determined based on the WHO clinical stage (stage I, II, III, and IV). Children's immunologic status is also determined using the WHO CD4 classification. CD4\% was categorized according to a modified version of the WHO Immunologic Classification for $\mathrm{HIV}$-associated immunodeficiency. It is classified into no evidence of immunosuppression if the CD4 count is 500 (>28\%) or more, mild immunosuppression if the CD4 count is between 350 and 499 (20-28\%), advanced immunosuppression if the CD4 count is between 200 and 349 (15-20\%), and severe immunosuppression if the CD4 count is less than $200(<15 \%)$ [21-23].

The anthropometric status of children was determined by recording height, weight, and children's age from records of ART cards. Then using nutrition software WHO Anthro and WHO AnthroPlus, the nutritional status of children was determined. Height-for-age Z-score (HAZ), weight-for-age $\mathrm{Z}$-score (WAZ), and body mass index- (BMI-) for-age scores of less than -2 SD were considered as stunted, underweight, and wasted, respectively. Those children with a HAZ, WAZ, or BMI score less than -3 SD were considered as severely stunted, underweight, and wasted, respectively [24].

Four health professionals and two public health supervisors were recruited for data collection. The training was given on the data collection process and ethical issues. Continuous supervision and follow-up of the data collectors were done. The collected data were handled and stored carefully and appropriately.

2.5. Data Processing and Analysis. Data were checked for incompleteness and inconsistency, edited, cleaned, coded, and entered into EpiData version 3.1, and exported to SPSS version 22 for analysis. Descriptive statistics were used to summarize the characteristics of study participants. A paired sample $t$-test was used to assess whether there is a significant difference in hemoglobin level, BMI, and CD4 count pre- and post-ART. Multivariable logistic regression was used to identify independent predictors of anemia among children receiving antiretroviral therapy. The strength of association was measured through odds ratios at their $95 \%$ confidence interval. Predictor variables with a $p$ value of $<0.25$ at bivariable analysis were included in the multivariable logistic regression model and analyzed using the backward stepwise elimination. $p$ value $<0.05$ was used to declare statistical significance.

Multicollinearity was checked using the standard error value. Variables having a standard error value of two or more will be considered having multicollinearity, but no variables 


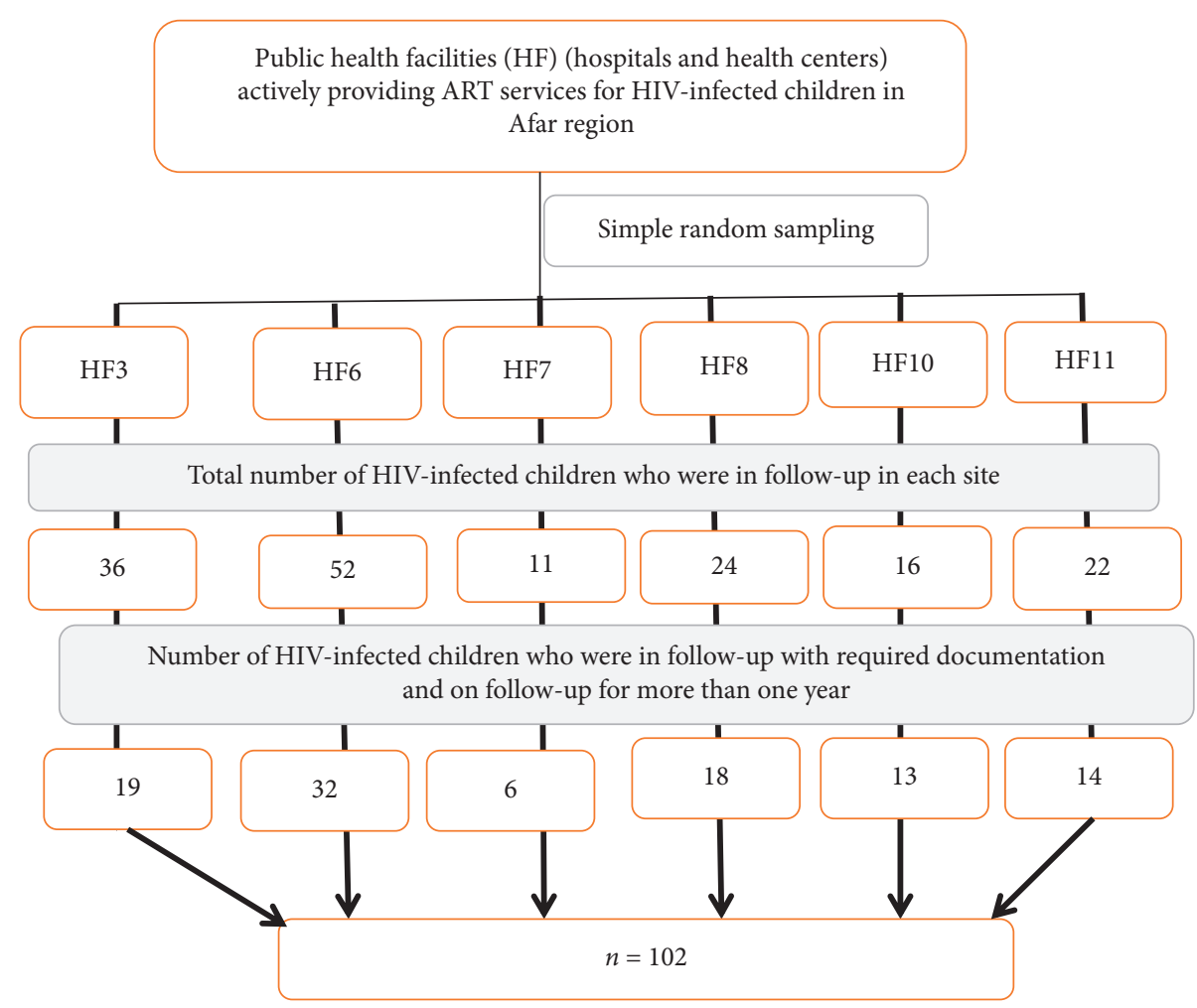

FIGURE 1: Flow diagram (sampling procedure) for selecting study participants.

were found with it. The percentage of the model that was accurately classified was $67 \%$ with Hosmer and Lemeshow goodness-of-fit test $(p$ value $=0.605)$, indicating the model fits well.

\section{Result}

Characteristics of study participants: a total of 102 children participated in this study. From those, 67 (65.7\%) children were school age and above, while 35 (34.3\%) were preschool age. More than half of children 56 (54.9\%) were male (Table 1).

Nutritional status of study participants: at baseline, 29 (28.4\%), $56(54.9 \%)$, and $22(21.6 \%)$ of study participants were underweight, stunted, and wasted, respectively (Table 2).

Children's HIV status: dealing with the WHO clinical stage of children, 30 (29.4\%) and 20 (19.6\%) children were in clinical stage I and IV, respectively. More than half of children (61 (59.8\%)) had a history of immunosuppression, and $50(49 \%)$ children had a history of opportunistic infections (Table 3 ).

Comparison of some characteristics of study subjects preand one year post-ART: at baseline, $53.9 \%$ of study participants were anemic ( $8.7 \%$ mild, $36.3 \%$ moderate, and $9.8 \%$ severe), while after a year course of HAART therapy, $46 \%$ of children were anemic (23\% mild, 18\% moderate, and 5\% severe). At presentation, before the initiation of HAART, out of all study participants, $28.4 \%$ of children were underweight, $54.9 \%$ were stunted, and $21.6 \%$ were wasted (Table 4 ).

There was a statistically significant improvement in the hemoglobin level following the one-year course of ART treatment from $10.67 \pm 1.82$ to $11.5 \pm 1.5$ ( $p$ value $\leq 0.001)$ : an improvement of $0.83 \pm 1.74$. There is also a statistical improvement of CD4 count from $397.8 \pm 233.9$ to $568.3 \pm 326.9$ ( $p$ value $\leq 0.001$ ): an improvement of $170.5+171.4$ (Table 5 ).

Factors associated with anemia status: in this study, the magnitude of anemia at baseline was found to be $53.9 \%$ (95\% CI $(44.1,63.7))$. Children who were moderately and severely stunted were more than five $(\mathrm{AOR}=5.16,95 \% \mathrm{CI}(1.71$, 15.56) ) and more than twelve $(\mathrm{AOR}=12.45,95 \% \mathrm{CI}(2.62$, 59.21)) times more likely to be anemic than children who were not stunted, respectively. Children whose mothers had not attended ANC follow-up for the index child were more than three and a half $(\mathrm{AOR}=3.68,95 \% \mathrm{CI}(1.38,9.81))$ times more likely to be anemic than children whose mothers attended ANC. Children who were in clinical stage 3 and 4 were more than five $(\mathrm{AOR}=5.07,95 \% \mathrm{CI}(1.79,14.37))$ times more likely to be anemic than children who were in clinical stage 1 and 2 (Table 6).

\section{Discussion}

This study was aimed to identify the magnitude of anemia and its associated factors among HIV-infected children in pastoralist settings (Afar region), northeast part of Ethiopia. According to this study, the magnitude of anemia among HIV-positive children was found to be $53.9 \%$, which is important public health significance. This is slightly lower than the reports of studies done among HIV-positive children in Harer [25] and India [7], which were 54.4\% and $66.0 \%$, respectively. On the other hand, this finding is higher than the studies done among HIV-positive children in 
TABLE 1: Characteristics of the study participants by anemia status of HIV-infected children aged 6 months to 15 years, in the Afar region, Ethiopia, 2018.

\begin{tabular}{|c|c|c|c|c|c|}
\hline \multirow{2}{*}{ Variable } & \multirow{2}{*}{ Category } & \multicolumn{3}{|c|}{ Anemia status } & \multirow{2}{*}{$p$ value } \\
\hline & & Yes, $n(\%)$ & No, $n(\%)$ & Total, $n(\%)$ & \\
\hline \multirow{2}{*}{ Child age } & Preschool age ( $<7$ years) & $17(30.9)$ & $18(38.3)$ & $35(34.3)$ & \multirow{2}{*}{0.433} \\
\hline & School age and above ( $\geq 7$ years) & $38(69.1)$ & $29(61.7)$ & $67(65.7)$ & \\
\hline \multirow{2}{*}{ Child sex } & Male & $25(45.5)$ & $31(66)$ & $56(54.9)$ & \multirow{2}{*}{0.038} \\
\hline & Female & $30(54.5)$ & $16(34)$ & $46(45.1)$ & \\
\hline \multirow{2}{*}{ Residence } & Rural & $45(81.8)$ & $36(76.6)$ & $81(79.4)$ & \multirow{2}{*}{0.516} \\
\hline & Urban & $10(18.2)$ & $11(23.4)$ & $21(20.6)$ & \\
\hline
\end{tabular}

TABLE 2: Pre-ART nutritional status of study participants by anemia status of HIV-infected children aged 6 months to 15 years, in the Afar region, Ethiopia, 2018.

\begin{tabular}{|c|c|c|c|c|c|}
\hline \multirow{2}{*}{ Variable } & \multirow{2}{*}{ Category } & \multicolumn{3}{|c|}{ Anemia status } & \multirow{2}{*}{$p$ value } \\
\hline & & Yes, $n(\%)$ & No, $n(\%)$ & Total, $n(\%)$ & \\
\hline \multirow{2}{*}{ Underweight } & Yes & $18(32.7)$ & $11(23.4)$ & $29(28.4)$ & \multirow{2}{*}{0.298} \\
\hline & No & $37(67.3)$ & $36(76.6)$ & $73(71.6)$ & \\
\hline \multirow{2}{*}{ Underweight classification $(n=29)$} & Moderate & $11(20)$ & $8(17)$ & $19(18.6)$ & \multirow{2}{*}{$0.411^{*}$} \\
\hline & Severe & $7(12.7)$ & $3(6.4)$ & $10(9.8)$ & \\
\hline \multirow{2}{*}{ Stunting } & Yes & $40(72.7)$ & $16(34)$ & $56(54.9)$ & \multirow{2}{*}{$<0.001$} \\
\hline & No & $15(27.3)$ & $31(66)$ & $46(45.1)$ & \\
\hline \multirow{2}{*}{ Stunting classification $(n=56)$} & Moderate & $25(45.4)$ & $13(27.7)$ & $38(37.2)$ & \multirow{2}{*}{$0.149^{*}$} \\
\hline & Severe & $15(27.3)$ & $3(6.4)$ & $18(17.7)$ & \\
\hline \multirow{2}{*}{ Wasting } & Yes & $12(21.8)$ & $10(21.3)$ & $22(21.6)$ & \multirow{2}{*}{0.947} \\
\hline & No & $43(78.2)$ & $37(78.7)$ & $80(78.4)$ & \\
\hline \multirow{2}{*}{ Wasting classification $(n=22)$} & Moderate & $8(14.5)$ & $8(17)$ & $16(15.6)$ & \multirow{2}{*}{$0.417^{*}$} \\
\hline & Severe & $4(7.3)$ & $2(4.3)$ & $6(5.8)$ & \\
\hline
\end{tabular}

Moderate $=$ weight-for-age, height-for-age, and weight-for-height $Z$-score $<-2 \mathrm{SD}$; severe $=Z$-score $<-3 \mathrm{SD} .{ }^{*}$ Fisher's exact test.

TABle 3: Children's HIV status by anemia status of HIV-infected children aged 6 months to 15 years, in the Afar region, Ethiopia, 2018.

\begin{tabular}{|c|c|c|c|c|c|}
\hline \multirow{2}{*}{ Variables } & \multirow{2}{*}{ Category } & \multicolumn{3}{|c|}{ Anemia status } & \multirow{2}{*}{$p$ value } \\
\hline & & Yes, $n(\%)$ & No, $n(\%)$ & Total, $n(\%)$ & \\
\hline \multirow{4}{*}{ WHO clinical stage } & I & $13(23.6)$ & $17(36.2)$ & $30(29.4)$ & \multirow{4}{*}{0.011} \\
\hline & II & $8(14.5)$ & $16(34)$ & $24(23.5)$ & \\
\hline & III & $19(34.5)$ & $9(19.1)$ & $28(27.5)$ & \\
\hline & IV & $15(27.3)$ & $5(10.6)$ & $20(19.6)$ & \\
\hline \multirow{3}{*}{ Immunosuppression } & Yes & $40(72.7)$ & $21(44.7)$ & $61(59.8)$ & \multirow{3}{*}{0.004} \\
\hline & No & $15(27.3)$ & $26(55.3)$ & $41(40.2)$ & \\
\hline & Mild & $13(23.6)$ & $13(27.7)$ & $26(25.5)$ & \\
\hline \multirow[t]{2}{*}{ Immunosuppression grade $(n=61)$} & Advanced & $13(23.6)$ & $6(12.8)$ & $19(18.6)$ & \multirow[t]{2}{*}{0.044} \\
\hline & Severe & $14(25.5)$ & $2(4.2)$ & $16(15.7)$ & \\
\hline \multirow{2}{*}{ Opportunistic infection } & Yes & $33(60)$ & $17(36.2)$ & $50(49)$ & \multirow{2}{*}{0.016} \\
\hline & No & $22(40)$ & $30(63.8)$ & $52(51)$ & \\
\hline \multirow{2}{*}{$\mathrm{TB}$} & Yes & $8(14.5)$ & $4(8.5)$ & $12(11.8)$ & \multirow{2}{*}{0.346} \\
\hline & No & $47(85.5)$ & $43(91.5)$ & $90(88.2)$ & \\
\hline \multirow{2}{*}{ Childhood illness } & Yes & $33(60)$ & $25(53.2)$ & $58(56.9)$ & \multirow{3}{*}{0.489} \\
\hline & No & $22(40)$ & $22(46.8)$ & $44(43.1)$ & \\
\hline \multirow{3}{*}{ Duration on HAART } & $<2$ years & $6(10.9)$ & $8(17)$ & $14(13.7)$ & \\
\hline & $2-5$ years & $18(32.7)$ & $12(25.5)$ & $30(29.4)$ & \multirow[t]{2}{*}{0.565} \\
\hline & $>5$ years & $31(56.4)$ & $27(57.5)$ & $58(56.9)$ & \\
\hline \multirow{2}{*}{ ANC follow-up for the index child } & Yes & $16(29.1)$ & $29(61.7)$ & $45(44.1)$ & \multirow{2}{*}{$<0.001$} \\
\hline & No & $39(70.9)$ & $18(38.3)$ & $57(55.9)$ & \\
\hline
\end{tabular}

Gondar [13], Addis Ababa [26], and Uganda [27]. This difference might be due to the age differences and study design used and other sociodemographic characteristics. The finding of this study is also in line with EDHS 2005, 2011, and 2016 reports, in which the prevalence of anemia among
non-HIV-infected children aged 6-59 months is 53\%, 44\%, and 57\%, respectively [28].

Even though, there is a statistically significant improvement in the hemoglobin level from baseline, the prevalence after one-year course of ART is still high (42.1\%). 
TABLE 4: Comparison of selected variables using Pearson's chi-square test before the initiation of ART and one year after the initiation of ART regimen.

\begin{tabular}{|c|c|c|c|c|}
\hline Variable & Category & At baseline (pre-ART) & After one-year course of HAART treatment & Pearson's chi-square \\
\hline \multirow{2}{*}{ Anemia } & Yes & $55(53.9)$ & $42(41.2)$ & \multirow{2}{*}{0.015} \\
\hline & No & $47(46.1)$ & $60(58.8)$ & \\
\hline \multirow{2}{*}{ Stunting } & Yes & $56(54.9)$ & $53(48)$ & \multirow[b]{2}{*}{$<0.001$} \\
\hline & No & $46(45.1)$ & $49(52)$ & \\
\hline \multirow{2}{*}{ Wasting } & Yes & $22(21.6)$ & $18(17.6)$ & \multirow{2}{*}{0.003} \\
\hline & No & $80(78.4)$ & $84(82.4)$ & \\
\hline \multirow{2}{*}{ Underweight } & Yes & $29(28.4)$ & $22(21.6)$ & \multirow{2}{*}{$<0.001$} \\
\hline & No & $73(71.6)$ & $80(78.4)$ & \\
\hline
\end{tabular}

TABLE 5: Comparison of selected variables using paired sample $t$-test before the initiation of ART and one year after the initiation of ART regimen.

\begin{tabular}{lccccccccc}
\hline \multirow{2}{*}{ Variable } & \multicolumn{2}{c}{ Pre-ART } & \multicolumn{2}{c}{ Post-ART } & \multicolumn{3}{c}{ Paired sample $t$-test } \\
& Mean & SD & Mean & SD & Mean difference & SD & $t$-value & Df** & $p$ value \\
\hline Hemoglobin level & 10.67 & 1.82 & 11.50 & 1.50 & -0.83 & 1.74 & -4.810 & 101 & $<0.001$ \\
CD4 count & 397.83 & 233.99 & 568.34 & 326.90 & -170.51 & 171.39 & -10.047 & 101 & $<0.001$ \\
BMI & 14.73 & 1.38 & 15.23 & 1.46 & -0.50 & 1.11 & -4.545 & 101 & $<0.001$ \\
\hline
\end{tabular}

${ }^{*}$ Standard deviation; ${ }^{* *}$ degree of freedom.

TABLE 6: Factors associated with anemia status of HIV-infected children aged 6 months to 15 years, in the Afar region, Ethiopia, 2018.

\begin{tabular}{|c|c|c|c|c|}
\hline \multirow{2}{*}{ Variables/category } & \multicolumn{2}{|c|}{ Anemia status } & \multirow{2}{*}{ COR $(95 \% \mathrm{CI})$} & \multirow{2}{*}{$\operatorname{AOR}(95 \% \mathrm{CI})$} \\
\hline & Yes, $n(\%)$ & No, $n(\%)$ & & \\
\hline \multicolumn{5}{|l|}{ Sex } \\
\hline Male & $25(45.5)$ & $31(66)$ & 1 & \\
\hline Female & $30(54.5)$ & $16(34)$ & $2.32(1.04,5.19)$ & \\
\hline \multicolumn{5}{|l|}{ Stunting } \\
\hline No & $15(27.3)$ & $31(66)$ & 1 & 1 \\
\hline Moderate & $25(45.4)$ & $13(27.7)$ & $3.97(1.60,9.88)$ & $5.16(1.71,15.56)$ \\
\hline Severe & $15(27.3)$ & $3(6.4)$ & $10.33(2.59,41.25)$ & $12.45(2.62,59.21)$ \\
\hline \multicolumn{5}{|c|}{ ANC follow-up for the index child } \\
\hline Yes & $16(29.1)$ & $29(61.7)$ & 1 & 1 \\
\hline No & $39(70.9)$ & $18(38.3)$ & $3.92(1.72,8.98)$ & $3.68(1.38,9.81)$ \\
\hline \multicolumn{5}{|c|}{ Evidence of immunosuppression } \\
\hline No & $15(27.3)$ & $26(55.3)$ & 1 & - \\
\hline Yes & $40(72.7)$ & $21(44.7)$ & $3.30(1.44,7.54)$ & - \\
\hline \multicolumn{5}{|l|}{ WHO clinical stage } \\
\hline Stage 1 and 2 & $21(38.2)$ & $33(70.2)$ & 1 & 1 \\
\hline Stage 3 and 4 & $34(61.8)$ & $14(29.8)$ & $3.81(1.66,8.74)$ & $5.07(1.79,14.37)$ \\
\hline \multicolumn{5}{|c|}{ Opportunistic infections ${ }^{*}$} \\
\hline No & $22(40)$ & $30(63.8)$ & 1 & - \\
\hline Yes & $33(60)$ & $17(36.2)$ & $2.64(1.18,5.91)$ & - \\
\hline
\end{tabular}

*Pulmonary TB, candidiasis, otitis media, toxoplasmosis, pneumocystis carinii pneumonia, cytomegalovirus, and herpes simplex virus were the common opportunistic infections seen in children.

This could be as our final model shows as the WHO clinical stage is one factor for anemia (other duration goes the likely to progress into the next stage might be high). The other is the infection by itself decreases the appetite, altered absorption, concurrent illness such as malaria and hookworm, and other infections [12-14].

In this study, anemia was independently associated with the nutritional status of children (specifically stunting), WHO clinical stage, and history of ANC follow-up. Children who were stunted were more likely to be anemic than children who were not stunted. Other studies that had done in Ethiopia [25], India [7, 29], and Uganda [27] support this finding. HIV-infected children were likely to have increased nutritional requirements, poor appetite, and reduced intake due to illness and socioeconomic factors [30]. The WHO recommends a $10 \%$ increase in energy intake for asymptomatic HIV-infected children, with further increases of 20 to $30 \%$ and 50 to $100 \%$ for those children who are symptomatic and experiencing weight loss, respectively [30]. Nutritional deficiencies may prone the child to opportunistic 
infections, and parasitic infestations may result in increased losses, and the presence of chronic infection may depress erythropoiesis $[7,31]$. The other possible explanation could be the concomitant occurrence of stunting and anemia due to diminished requirements of micronutrients [32-34].

This study also showed that children whose mothers did not attend ANC follow-up were more likely to be anemic than children whose mothers attended ANC. This can be explained by the fact that during ANC follow-up, a mother could use prevention of mother-to-child transmission (PMTCT) services $[35,36]$, by which viral load might be decreased and the effective use of HAART might reduce the progression to advanced HIV/AIDS stage [37]. The other possible reason could be that during ANC follow-up, a mother could get nutritional counseling services, which prevents the occurrence of micronutrient deficiencies like iron and vitamin A.

Lastly, children who were in clinical stage 3 and 4 were more likely to be anemic than children who were in clinical stage 1 and 2. The finding of this study is in line with studies done in Ethiopia [25] and India [7]. The possible explanation for this could be that advanced HIV disease may be associated with deficiencies of other micronutrients in children, such as vitamin $A$, which is thought to have a role in erythropoiesis and iron transport [38]. The other reason can be as HIV progress to advanced stage, the presence of opportunistic infections could further compound anemia [39].

\section{Conclusion}

This study concludes that the magnitude of anemia among HIV-infected children was found to be high, which is $53.9 \%$. Stunting, WHO clinical stage, and history of ANC follow-up were the predictors significantly associated with childhood anemia. There is also a statistically significant improvement in the hemoglobin level and CD4 count following the one-year course of HAART treatment. Thus, interventions for HIV-positive children should consider those factors.

\section{Abbreviations}

AOR: $\quad$ Adjusted odds ratio

ART: Antiretroviral therapy

CBC: Complete blood count

CI: $\quad$ Confidence interval

EpiData: Epidemiological information

HAART: Highly active antiretroviral therapy

HIV: Human immunodeficiency virus

MUAC: Mid-upper arm circumference

LZA: Length-for-age Z-score

SPSS: $\quad$ Statistical Package for Social Science

UNICEF: United Nations Children's Fund

WHO: World Health Organization.

\section{Data Availability}

The data used to support the findings of this study are available from the corresponding author upon request.

\section{Ethical Approval}

Ethical approval was obtained from the Institutional Review Board of the College of Medical and Health Sciences, Samara University (protocol approval: ERC-0459/2018). An official letter of support was obtained from the Afar Regional Health Bureau. The objectives of the study were explained to the health professionals working in the ART sites. Data were collected using codes, not the name of study participants. Privacy and confidentiality of collected information were ensured at all levels.

\section{Disclosure}

Samara University (funder) had no role in the study design, data collection, and analysis, decision to publish, or preparation of the manuscript.

\section{Conflicts of Interest}

The authors declare that they have no conflicts of interest.

\section{Authors' Contributions}

FM, GFM, and HGA conceived and designed the study, performed analysis, and interpreted the data. GFM prepared the manuscript, and all authors read and approved the final manuscript.

\section{Acknowledgments}

The authors would like to express their deepest gratitude to Samara Universities for providing ethical approval for this study. Our appreciation also goes to data collectors and supervisors. Lastly, our heartfelt thanks go to health workers for their cooperation in reviewing patient cards.

\section{References}

[1] M. Abebe and F. Alemseged, "Hematologic abnormalities among children on HAART, in Jimma University specialized hospital, southwestern Ethiopia," Ethiopian Journal of Health Sciences, vol. 19, no. 2, 2009.

[2] WHO, UNICEF, and UNU, Iron Deficiency Anaemia Assessment, Prevention and Control: A Guide for Programme Managers, WHO, Geneva, Switzerland, 1993.

[3] P. A. Volberding, A. M. Levine, D. Dieterich, D. Mildvan, R. Mitsuyasu, and M. Saag, "Anemia in HIV infection: clinical impact and evidence-based management strategies," Clinical Infectious Diseases, vol. 38, no. 10, pp. 1454-1463, 2004.

[4] E. N. Ruhinda, F. Bajunirwe, and J. Kiwanuka, "Anaemia in HIV-infected children: severity, types and effect on response to HAART," BMC Pediatrics, vol. 12, no. 1, p. 170, 2012.

[5] J. D. Lundgren and A. Mocroft, "Anemia and survival in human immunodeficiency virus," Clinical Infectious Diseases, vol. 37, no. 4, pp. S297-S303, 2003.

[6] A. Mocroft, O. Kirk, S. E. Barton et al., "Anaemia is an independent predictive marker for clinical prognosis in HIVinfected patients from across Europe," AIDS, vol. 13, no. 8, pp. 943-950, 1999. 
[7] A. Anita, S. Mehta, N. Rajagopalan et al., "Anemia and growth failure among HIV-infected children in India: a retrospective analysis," BMC Pediatrics, vol. 9, no. 1, p. 37, 2009.

[8] M. E. Brien, R. Kupka, G. I. Msamanga et al., "Anemia is an independent predictor of mortality and immunologic progression of disease among women with HIV in Tanzania," JAIDS Journal of Acquired Immune Deficiency Syndromes, vol. 40, no. 2, pp. 219-225, 2005.

[9] A. G. Alamdo, T. Fiseha, A. Tesfay, M. K. Deber, Z. M. Tirfe, and T. Tilahun, "Anemia and its associated risk factors at the time of antiretroviral therapy initiation in public health facilities of Arba Minch Town, Southern Ethiopia," Health, vol. 7, no. 12, pp. 1657-1664, 2015.

[10] R. Subbaraman, B. Devaleenal, P. Selvamuthu et al., "Factors associated with anaemia in HIV-infected individuals in Southern India," International Journal of STD \& AIDS, vol. 20, no. 7, pp. 489-492, 2009.

[11] R. D. Semba and G. E. Gray, "Pathogenesis of anemia during human immunodeficiency virus infection," Journal of Investigative Medicine, vol. 49, no. 3, pp. 225-239, 2001.

[12] P. S. Belperio and D. C. Rhew, "Prevalence and outcomes of anemia in individuals with human immunodeficiency virus: a systematic review of the literature," The American Journal of Medicine, vol. 116, no. 7, pp. 27-43, 2004.

[13] B. Enawgaw, M. Alem, M. Melku, Z. Addis, B. Terefe, and G. Yitayew, "Prevalence and associated risk factors of anemia among HIV infected children attending Gondar University Hospital, Northwest Ethiopia: a cross sectional study," BMC Hematology, vol. 15, no. 1, p. 12, 2015.

[14] B. F. Sunguya, K. C. Poudel, K. Otsuka et al., "Undernutrition among HIV-positive children in Dar es Salaam, Tanzania: antiretroviral therapy alone is not enough," BMC Public Health, vol. 11, no. 1, p. 869, 2011.

[15] Y. Balarajan, U. Ramakrishnan, E. Özaltin, A. H. Shankar, and S. Subramanian, "Anaemia in low-income and middle-income countries," The Lancet, vol. 378, no. 9809, pp. 2123-2135, 2011.

[16] World Health Organization, Iron Deficiency Anemia. Assessment, Prevention, and Control. A Guide for Programme Managers, pp. 47-62, World Health Organization, Geneva, Switzerland, 2001.

[17] B. Enawgaw, Y. Workineh, S. Tadesse, E. Mekuria, A. Addisu, and M. Genetu, "Prevalence of anemia and associated factors among hospitalized children attending the University of Gondar Hospital, Northwest Ethiopia," The Electronic Journal of the IFCC, vol. 30, no. 1, pp. 35-47, 2019.

[18] N. A. Moges and G. M. Kassa, "Prevalence of opportunistic infections and associated factors among HIV positive patients taking anti-retroviral therapy in DebreMarkos Referral Hospital, Northwest Ethiopia," Journal of AIDS \& Clinical Research, vol. 5, no. 5, pp. 1-300, 2014.

[19] J. Chinkhumba, A. Tomkins, T. Banda, C. Mkangama, and P. Fergusson, "The impact of HIV on mortality during inpatient rehabilitation of severely malnourished children in Malawi," Transactions of the Royal Society of Tropical Medicine and Hygiene, vol. 102, no. 7, pp. 639-644, 2008.

[20] J. Zhou, A. Jaquet, E. Bissagnene et al., "Short-term risk of anaemia following initiation of combination antiretroviral treatment in HIV-infected patients in countries in subSaharan Africa, Asia-Pacific, and Central and South America," Journal of the International AIDS Society, vol. 15, no. 1, p. $5,2012$.

[21] World Health Organization, "Haemoglobin concentrations for the diagnosis of anemia and assessment of severity:
VMNIS| vitamin and mineral nutrition information system," Report of a WHO Scientific Group World Health Organization, Geneva, Switzerland, 2011.

[22] J. Edathodu, B. Ali, and A. A. Alrajhi, "CD4 validation for the World Health Organization classification and clinical staging of HIV/AIDS in a developing country," International Journal of Infectious Diseases, vol. 13, no. 2, pp. 243-246, 2009.

[23] D. E. Yin, M. G. Warshaw, W. C. Miller et al., "Using CD4 percentage and age to optimize pediatric antiretroviral therapy initiation," Pediatrics, vol. 134, no. 4, pp. e1104-e1116, 2014.

[24] World Health Organization, WHO Child Growth Standards: Length/height-For-Age, Weight-For-Age, Weight-For-Length, Weight-For-Height and Body Mass Index-For-Age: Methods and Development, World Health Organization, Geneva, Switzerland, 2006.

[25] Z. Teklemariam, F. Mesfin, and H. Mitiku, "Prevalence of anemia and nutritional status among HIV-positive children receiving antiretroviral therapy in Harar, Eastern Ethiopa," HIV/AIDS-Research and Palliative Care, vol. 7, pp. 1-6, 2015.

[26] H. Mihiretie, B. Taye, and A. Tsegaye, "Magnitude of anemia and associated factors among pediatric HIV/AIDS patients attending Zewditu Memorial Hospital Art Clinic, Addis Ababa, Ethiopia," Anemia, vol. 2015, 2015.

[27] I. D. Legason, A. Atiku, R. Ssenyonga, P. Olupot-Olupot, and J. B. Barugahare, "Prevalence of anaemia and associated risk factors among children in North-Western Uganda: a cross sectional study," BMC Hematology, vol. 17, no. 1, p. 10, 2017.

[28] C. A. Gewa, S. P. Murphy, R. E. Weiss, and C. G. Neumann, "Determining minimum food intake amounts for diet diversity scores to maximize associations with nutrient adequacy: an analysis of schoolchildren's diets in rural Kenya," Public Health Nutrition, vol. 17, no. 12, pp. 2667-2673, 2014.

[29] S. Rajasekaran, L. Jeyaseelan, N. Ravichandran, C. Gomathi, F. Thara, and C. Chandrasekar, "Efficacy of antiretroviral therapy program in children in India: prognostic factors and survival analysis," Journal of Tropical Pediatrics, vol. 55, no. 4, pp. 225-232, 2008.

[30] WHO, "Nutrient requirements for people living with HIV/ AIDS: report of a technical consultation," World Health Organization, Geneva, Switzerland, 2003.

[31] J. C. Calis, M. B. van Hensbroek, R. J. de Haan, P. Moons, B. J. Brabin, and I. Bates, "HIV-associated anemia in children: a systematic review from a global perspective," AIDS, vol. 22, no. 10, pp. 1099-1112, 2008.

[32] S. Ehrhardt, G. D. Burchard, C. Mantel et al., "Malaria, anemia, and malnutrition in african children-defining intervention priorities," The Journal of Infectious Diseases, vol. 194, no. 1, pp. 108-114, 2006.

[33] I. S. Otchwemah, J. C. Daneluzzi, H. Vannucchi et al., "Prevalência da carência de ferro e sua associação com a deficiência de vitamina A em pré-escolares," Jornal de Pediatria, vol. 81, no. 2, pp. 169-174, 2005.

[34] M. Martinelli, D. Sala, M. Usuelli et al., "Double-blind, placebo-controlled trial comparing effects of supplementation with two different combinations of micronutrients delivered as sprinkles on growth, anemia, and iron deficiency in Cambodian infants," Journal of Pediatric Gastroenterology and Nutrition, vol. 42, no. 3, pp. 306-312, 2006.

[35] A. Radaelli and G. Mitike, "Prevention of mother-to-child transmission (PMTCT) of HIV services in Adama town, Ethiopia: clients' satisfaction and challenges experienced by service providers," BMC Pregnancy and Childbirth, vol. 14, no. 1, p. 57, 2014. 
[36] A. Feyera, B. Megerssa, D. Legesse, and F. Hailemichael, "Prevention of mother to child transmission of HIV/AIDS: service utilization and associated factors among selected public health facilities in Ethiopia," Medical Practice and Reviews, vol. 8, no. 1, pp. 1-13, 2017.

[37] J. S. Montaner, V. D. Lima, P. R. Harrigan et al., "Expansion of HAART coverage is associated with sustained decreases in HIV/AIDS morbidity, mortality and HIV transmission: the "HIV treatment as prevention" experience in a Canadian setting," PLoS One, vol. 9, no. 2, 2014.

[38] M. B. Zimmermann, R. Biebinger, F. Rohner et al., "Vitamin A supplementation in children with poor vitamin A and iron status increases erythropoietin and hemoglobin concentrations without changing total body iron," The American Journal of Clinical Nutrition, vol. 84, no. 3, pp. 580-586, 2006.

[39] S. Chaouki, C. Padmapriyadarsini, B. Sukumar et al., "Nutritional status of persons with HIV infection, persons with HIV infection and tuberculosis, and HIV-negative individuals from southern India," Clinical Infectious Diseases, vol. 46, no. 6, pp. 946-949, 2008. 